Proceedings

\title{
Profile of Volatile Organic Compounds (VOCs) from Cold- Processed and Heat-Treated Virgin Coconut Oil (VCO) Samples ${ }^{\dagger}$
}

\author{
Ian Ken D. Dimzon, Grace B. Tantengco, Noel A. Oquendo and Fabian M. Dayrit *
}

Citation: Dimzon, I.K.D.; Tantengco, G.B.; Oquendo, N.A.; Dayrit, F.M. Profile of Volatile Organic Compounds (VOCs) from ColdProcessed and Heat-Treated Virgin Coconut Oil (VCO) Samples. Proceedings 2021, 70, 85. https://doi. org/10.3390/foods_2020-07723

Published: 10 November 2020

Publisher's Note: MDPI stays neutral with regard to jurisdictional claims in published maps and institutional affiliations.

\section{Copyright: $\odot 2020$ by the authors.} Licensee MDPI, Basel, Switzerland. This article is an open access article distributed under the terms and conditions of the Creative Commons Attribution (CC BY) license (http://creativecommons.org/licenses/by/4.0/).

\author{
Department of Chemistry, Ateneo de Manila University, Loyola Heights, Quezon City 1108, Philippines; \\ idimzon@ateneo.edu (I.K.D.D.); gbtantengco@gmail.com (C.B.T.); noquendo@ateneo.edu (N.A.O.) \\ * Correspondence: fdayrit@ateneo.edu \\ + Presented at the 1st International Electronic Conference on Food Science and Functional Foods, \\ 10-25 November 2020; Available online: https://foods_2020.sciforum.net/.
}

\begin{abstract}
Virgin coconut oil (VCO) can be prepared with or without heat. Fermentation and centrifuge processes can be done without the use of heat (cold process), while expelling involves heat due to friction. Volatile organic compounds (VOCs) from VCO samples prepared using these three methods were collected using solid phase microextraction (SPME) and analyzed using gas chromatography-mass spectrometry (GC-MS). Twenty-seven VCO samples from nine VCO producers were analyzed. The VOCs from refined, bleached, and deodorized coconut oil (RBDCO) were also obtained for comparison. Fourteen compounds were found to be common in more than $80 \%$ of the VCO samples analyzed. These included: Acetic acid; C6, C8, C10, C12, and C14 fatty acids, and their corresponding delta-lactones; and C8, C10 and C12 ethyl carboxylates. Fourteen minor VOCs were likewise detected which can be grouped into five types: Carboxylic acids (formic acid, butanoic acid, benzoic acid, and pentadecanoic acid), ketones (acetoin, 2-heptanone), an alcohol (ethanol), aldehydes (acetaldehyde, hexanal, benzaldehyde), esters (ethyl acetate, methyl tetradecanoate), and hydrocarbons (n-hexane and toluene). Five pyrazines were detected in expeller VCO. Various hydrocarbons from $\mathrm{C} 5$ to $\mathrm{C} 14$ were noted to be higher in old RBDCO and VCO samples. There were variations in the VOCs within each VCO process as each producer used different processing times, temperatures, and drying procedures. Principal components analysis (PCA) was able to group the samples according to the process used, but there were overlaps which may be due to variations in the specific procedures used by the manufacturers. These results may help VCO manufacturers control their production processes.
\end{abstract}

Keywords: virgin coconut oil (VCO); volatile organic compound (VOC); multivariate analysis; solid-phase microextraction-gas chromatography-mass spectrometry (SPME GC-MS)

\section{Introduction}

One who is familiar with the aroma of freshly produced virgin coconut oil (VCO) can easily tell how it is produced: Fresh and natural coconut aroma when cold-processed, or distinctly sweet coconut scent when heat-treated. VCO is obtained from the fresh mature meat of the coconut (Cocos nucifera L.) [1]. There are two ways to obtain the oil from the coconut kernel: (1) The wet method produces coconut milk, which is subsequently processed using fermentation or centrifugation; and (2) the dry method, which entails expelling the oil from coconut meat. In the wet method, heat is not required, hence this is called cold-processed. On the other hand, in the expeller process, heat is generated by friction.

The volatile organic compounds (VOCs) are responsible for the aroma of VCO. The VOCs can come from the coconut meat itself, the process of production, and from degradation processes that occur before, during, and after oil separation. 
The coconut meat is the main source of the volatile compounds. For example, seventeen compounds were identified from the unroasted coconut shreds analyzed by gas chromatography (GC) after distillation [2]. It included delta-lactones and ethyl carboxylates of $\mathrm{C} 8, \mathrm{C} 10$, and C12, which were thought to be responsible for the mild, sweet, and pleasant coconut flavor of unroasted coconut shreds.

Some VOCs can also come from various physico-chemical and microbiological processes during oil production and storage [1,3]. Among the notable pathways are the following [4]: (1) Formation and cleavage of hydroperoxides by lipoxygenases (LOX); (2) Maillard reaction; and (3) caramelization. LOX pathway reactions can be rapid at certain $\mathrm{pH}$ and temperature values. This pathway is responsible for the short-chain aldehydes and alcohols found in cold-pressed seeds. The Maillard reaction and caramelization are major routes for the formation of VOCs in VCO processes that involve heat in the presence of the meat or coconut milk. The Maillard reaction was suggested as the explanation for the formation of six pyrazines, two furans, and two pyrroles which were detected from the roasted coconut shreds [2]; these were thought to contribute to its uniquely strong, sweet, and nut-like scent.

During oven-drying of the coconut meat, oxidation and degradation of unsaturated lipids may contribute to the generation of aroma compounds, such as volatile alcohols, aldehydes, and ketones. Aliphatic methyl ketones and secondary alcohols were isolated from desiccated coconut [5] and were found to be responsible for the rancid off-flavor, particularly those with an odd number of carbon atoms, C5 to C11. 2-Heptanone and 2nonanone were present at the highest concentration in rancid coconut. In the VCO fermentation process, the production of acetic acid leads to a rancid odor. Volatile aldehydes, which are significant aroma compounds in vegetable oils, are formed from cleavage of lipid hydroperoxides; this also leads to formation of alcohols, alkanes, alkenes, and alkynes. Fresh coconut oil, subjected to different heat treatments, yielded volatiles of n-alkanes and 1-alkenes, n-alkanals, methyl alkanones, alkenals, gamma- and delta-lactones, methyl and ethyl esters, and free fatty acids. The relative amounts of these compounds varied with the type of heat treatment [6].

Previous analysis of VOCs from VCO samples prepared by three different methods detected 14 VOCs: Acetic acid, ethyl acetate, the delta-lactones and ethyl carboxylates of $\mathrm{C} 8$ and $\mathrm{C} 10$, the carboxylic acids of $\mathrm{C} 10$ and C12, aldehydes (hexanal, nonanal), ketones (2-pentanone and 2-heptanone), and a linear alkane (octane) and a monoterpene (limonene) [7].

\section{Research Objectives}

This work sought to identify and quantify the VOCs from VCO samples which were produced using three processes-fermentation, centrifuge, and expeller-as well as refined, bleached, and deodorized coconut oil (RBDCO). VCO samples were collected during on-site observation of each production process. Analysis of the VOC profiles from various stages of VCO production, as well as old VCO samples, will hopefully provide valuable information to VCO producers regarding the production process.

\section{Materials and Methods}

\subsection{VCO and RBDCO Samples}

Nine VCO manufacturers were visited to observe the manufacturing process. The VCO sample codes used are as follows: Fermentation (F1, F2, and F3), centrifuge (C1, C2, and C3), and expeller (E1, E2, and E3). Each producer utilized different methods and equipment to remove moisture and insoluble particles. Nine samples were submitted by the producers and 18 samples were collected during the observation visits (Table 1). The VCO samples were analyzed for their free fatty acid (\% FFA as lauric acid) and moisture contents. In addition, five RBDCO (frying oil) samples purchased from commercial stores and one 13-year old RBDCO sample were also analyzed for VOCs. 
Table 1. List of VCO samples * that were analyzed.

\begin{tabular}{ccc}
\hline Method of Production & Samples Submitted by Producers & Samples Collected during Production Process \\
\hline Fermentation & F1-0; F2-0; F3-0 & F1-1; F1-2; F2-1; F2-1; F3-1; F3-2 \\
Centrifuge & C1-0; C2-0; C3-0 & C1-1; C1-2; C2-1; C2-1; C3-1; C3-2 \\
Expeller & E1-0; E2-0; E3-0 & E1-1; E1-2; E2-1; E2-1; E3-1; E3-2 \\
\hline
\end{tabular}

* Sample codes: F: fermentation, C: centrifuge, E: expeller. F1, F2, F3: fermentation producer codes. F1-0, F1-1, F1-2: VCO samples from F1 producer.

3.2. Headspace Analysis by Solid-Phase Microextraction-Gas Chromatography-Mass Spectrometry (SPME-GCMS)

\subsubsection{Standards}

Acetic acid (100\%, Merck, Darmstadt, Germany); 2-heptanone (99\%, Fluka); octanoic acid (99\%, Sigma, St. Louis, MO, USA); ethyl octanoate (99\%, Aldrich); decanoic acid (99\%, Sigma); and dodecanoic acid (98\% Merck). 2-octanol (97\%, Sigma-Aldrich) was used as internal standard for calibration of GC retention time and quantitation.

\subsubsection{Sample Preparation}

The method from an earlier study [6] was used with modifications. About $5 \mathrm{~g}$ of the VCO sample were accurately weighed and spiked with $0.125 \mathrm{~g}$ of $0.02 \%$ 2-octanol in VCO matrix solution (internal standard, IS), into a 10-mL screw neck, clear vial with screw cap, Butyl/LTPE, $18 \mathrm{~mm}$ septum (Supelco, Bellefonte, PA, USA). The VCO matrix used in dilution of internal standard was treated with $3 \mathrm{M}$ sodium hydroxide and dried with anhydrous sodium sulfate.

\subsubsection{Analysis of \%Free Fatty Acids (\%FFAs) and \%Moisture Content}

\%FFAs was quantified based on lauric acid using the AOAC Official Method 940.28 (AOAC 1995). Moisture was measured by Karl Fischer titration following AOAC Official Method 984.20 (AOAC 1995).

\subsubsection{Headspace SPME and GC-MS Analysis}

SPME fiber used for extraction was the divinylbenzene-carboxen-polydimethylsiloxane (DVB/CAR/PDMS) fiber, 50/30 $\mu \mathrm{m}$, Stableflex, $24 \mathrm{Ga}$, Manual Holder (Supelco, Bellefonte, PA, USA). A length of $0.8 \mathrm{~cm}$ fiber was exposed to the headspace of the oil at $40{ }^{\circ} \mathrm{C}$ for $20 \mathrm{~min}$ and immediately desorbed into the injector port operating splitless at $250{ }^{\circ} \mathrm{C}$, while a short loop of the GC column was immersed in liquid nitrogen for $2 \mathrm{~min}$. All analyses were carried out using the Shimadzu GCMS-QP2010 Plus (Kyoto, Japan) with RTX-5MS ${ }^{\circledast}$ column (Restek, $30 \mathrm{~m} \times 0.25 \mathrm{~mm}$ i.d. $\times 0.25 \mu \mathrm{m}$ film thickness, Bellefonte, PA, USA) and ultra-high purity helium as carrier gas at $1.01 \mathrm{~mL} / \mathrm{min}$ flow rate. The oven temperature program was as follows: Initial temperature at $30^{\circ} \mathrm{C}$, hold for $10 \mathrm{~min}$, increase to $200{ }^{\circ} \mathrm{C}$ at $3{ }^{\circ} \mathrm{C} / \mathrm{min}$. The interface and the ion source temperatures were set at 300 and $200{ }^{\circ} \mathrm{C}$, respectively. MS analysis was carried out by electron ionization at $70 \mathrm{eV}$, scanning from $\mathrm{m} / \mathrm{z} 40$ to 240 . Identification of the GC peaks was carried out by comparison with the NIST library using a minimum similarity index of 90 . The fiber was cleaned after each use for $60 \mathrm{~min}$ at $250{ }^{\circ} \mathrm{C}$ under a stream of high purity $\mathrm{N}_{2}$ gas. Blank fiber analyses were done every after 10-20 runs.

\subsection{Principal Component Analysis}

Thirty-two samples with 60 variables were selected for principal component analysis (PCA). While most of the 60 variables were the individual major and minor VOCs detected in VCOs and RBDCOs, a few variables were groups of VOCs belonging to the same class or were isomers. No data pretreatment was done prior to analysis. PCA was done using 
JMP ${ }^{\circledR}$ Pro 14.3.0 (SAS Institute, Inc., Cary, NC, USA). Sparse estimation was used; it involves single value decomposition of a dataset with many zeros.

\section{Results}

\subsection{VCO Samples from Different Production Processes}

Table 2 shows the process flow of sample collection from the nine manufacturers visited and a short description of the critical steps: exposure, removal of moisture and particles, and sterilization. The \%moisture and \%free fatty acid (FFA, as lauric acid) content of the finished product are also given.

Table 2. Description of samples collected at VCO production sites.

\begin{tabular}{|c|c|c|c|c|c|c|}
\hline \multirow{2}{*}{ Sample a } & \multirow{2}{*}{$\begin{array}{l}\text { Exposure Time }{ }^{b} \\
\text { before Oil Separation }\end{array}$} & \multirow{2}{*}{$\begin{array}{c}\text { Method of Moisture } \\
\text { Removal from Raw } \\
\text { VCO }\end{array}$} & \multirow{2}{*}{$\begin{array}{c}\text { Method of Particles } \\
\text { Removal from Raw VCO }\end{array}$} & \multirow{2}{*}{ Sterilization/Heat Treatment } & \multicolumn{2}{|c|}{$\begin{array}{c}\text { Analysis of the Finished } \\
\text { Product }\end{array}$} \\
\hline & & & & & $\begin{array}{l}\text { \%Moisture } \\
\text { Content }\end{array}$ & $\%$ FFA \\
\hline F1-1 & \multirow{2}{*}{$>24 \mathrm{~h}$} & \multirow{2}{*}{ Tubular centrifuge } & \multirow{2}{*}{$\begin{array}{l}\text { Tubular centrifuge and fine } \\
\text { cloth filtration }\end{array}$} & \multirow{2}{*}{$\begin{array}{l}\text { Hot water for dilution of milk; } \\
\text { UV light on oil }\end{array}$} & 0.06 & $0.25^{\mathrm{c}}$ \\
\hline F1-2 & & & & & 0.08 & 0.20 \\
\hline F2-1 & \multirow{2}{*}{$<24 \mathrm{~h}$} & \multirow{2}{*}{$\begin{array}{c}\text { Tubular centrifuge and } \\
\text { vacuum drying }\end{array}$} & \multirow{2}{*}{ Tubular centrifuge } & \multirow{2}{*}{ Hot water for dilution of milk } & 0.10 & 0.13 \\
\hline F2-2 & & & & & 0.10 & 0.13 \\
\hline F3-1 & \multirow{2}{*}{$<24 \mathrm{~h}$} & \multirow{2}{*}{ Vacuum drying } & \multirow{2}{*}{$\begin{array}{c}0.5 \text { to } 1.0 \text { micron bag filtra- } \\
\text { tion }\end{array}$} & \multirow{2}{*}{ None } & 0.09 & 0.15 \\
\hline F3-2 & & & & & 0.10 & 0.12 \\
\hline C1-1 & \multirow{2}{*}{$<24 \mathrm{~h}$} & \multirow{2}{*}{ Disc centrifuge } & \multirow{2}{*}{ Paper filter } & \multirow{2}{*}{ Hot water to aid in separation } & 0.09 & 0.05 \\
\hline $\mathrm{C} 1-2$ & & & & & 0.10 & 0.05 \\
\hline $\mathrm{C} 2-1$ & \multirow{2}{*}{$<8 \mathrm{~h}$} & \multirow{2}{*}{ Disc centrifuge } & \multirow{2}{*}{ None } & \multirow{2}{*}{ None } & 0.10 & 0.09 \\
\hline $\mathrm{C} 2-2$ & & & & & $0.11^{\mathrm{c}}$ & 0.18 \\
\hline C3-1 & \multirow{2}{*}{$<8 \mathrm{~h}$} & \multirow{2}{*}{$\begin{array}{c}\text { Settling and vacuum dry- } \\
\text { ing }\end{array}$} & \multirow{2}{*}{ Settling } & \multirow{2}{*}{ Blanching of coconut meat } & 0.08 & 0.02 \\
\hline C3-2 & & & & & 0.08 & 0.01 \\
\hline E1-1 & \multirow{2}{*}{$<8 \mathrm{~h}$} & \multirow{2}{*}{$\begin{array}{c}\text { Settling, disc centrifuge, } \\
\text { and demoisturizer }\end{array}$} & \multirow{2}{*}{$\begin{array}{l}\text { Settling and } 0.5 \text { to } 1.0 \text { micron } \\
\text { bag filtration }\end{array}$} & \multirow{2}{*}{$\begin{array}{c}\text { Oven-drying of ground coconut } \\
\text { meat }\end{array}$} & 0.08 & 0.10 \\
\hline E1-2 & & & & & 0.09 & $0.38^{c}$ \\
\hline E2-1 & \multirow{2}{*}{$<8 \mathrm{~h}$} & \multirow{2}{*}{$\begin{array}{l}\text { Settling and vacuum dry- } \\
\text { ing }\end{array}$} & Settling, Pressure filter with & Oven-drying of grated coconut & $0.13^{c}$ & $0.33^{c}$ \\
\hline E2-2 & & & filter aids & meat & $0.12^{\mathrm{c}}$ & 0.17 \\
\hline E3-1 & & & & Oven-drying of ground coconut & 0.03 & 0.08 \\
\hline E3-2 & $<8 \mathrm{~h}$ & Vacuum drying & Filter press & meat & 0.04 & 0.07 \\
\hline
\end{tabular}

a Sample codes are given in Table 1; ${ }^{\mathrm{b}}$ Total time from the opening of coconut to oil separation; ${ }^{\mathrm{c}}$ Value is outside the standard specification for \%moisture and \%FFA [8].

The \%free fatty acid levels of F1-1, E1-2, and E2-1 exceeded the $0.20 \%$ FFA limit, and C2-2, E2-1, and E2-2 contained moisture higher than the 0.10\% limit set by the Philippine National Standard for Virgin Coconut Oil [8].

\subsection{Major VOCs of VCO}

Depicted in Figure 1a is a sample GC-MS total ion chromatogram (TIC), and the major VOCs are labeled: Hexanoic acid, delta-caprolactone, octanoic acid, ethyl octanoate, deltaoctalactone, n-decanoic acid, ethyl decanoate, delta-decalactone, dodecanoic acid, ethyl dodecanoate, delta-dodecalactone, tetradecanoic acid, and delta-tetradecalactone; these are all of C6, C8, C10, C12, and C14 compounds. The structures are drawn in Figure $1 \mathrm{~b}$. 


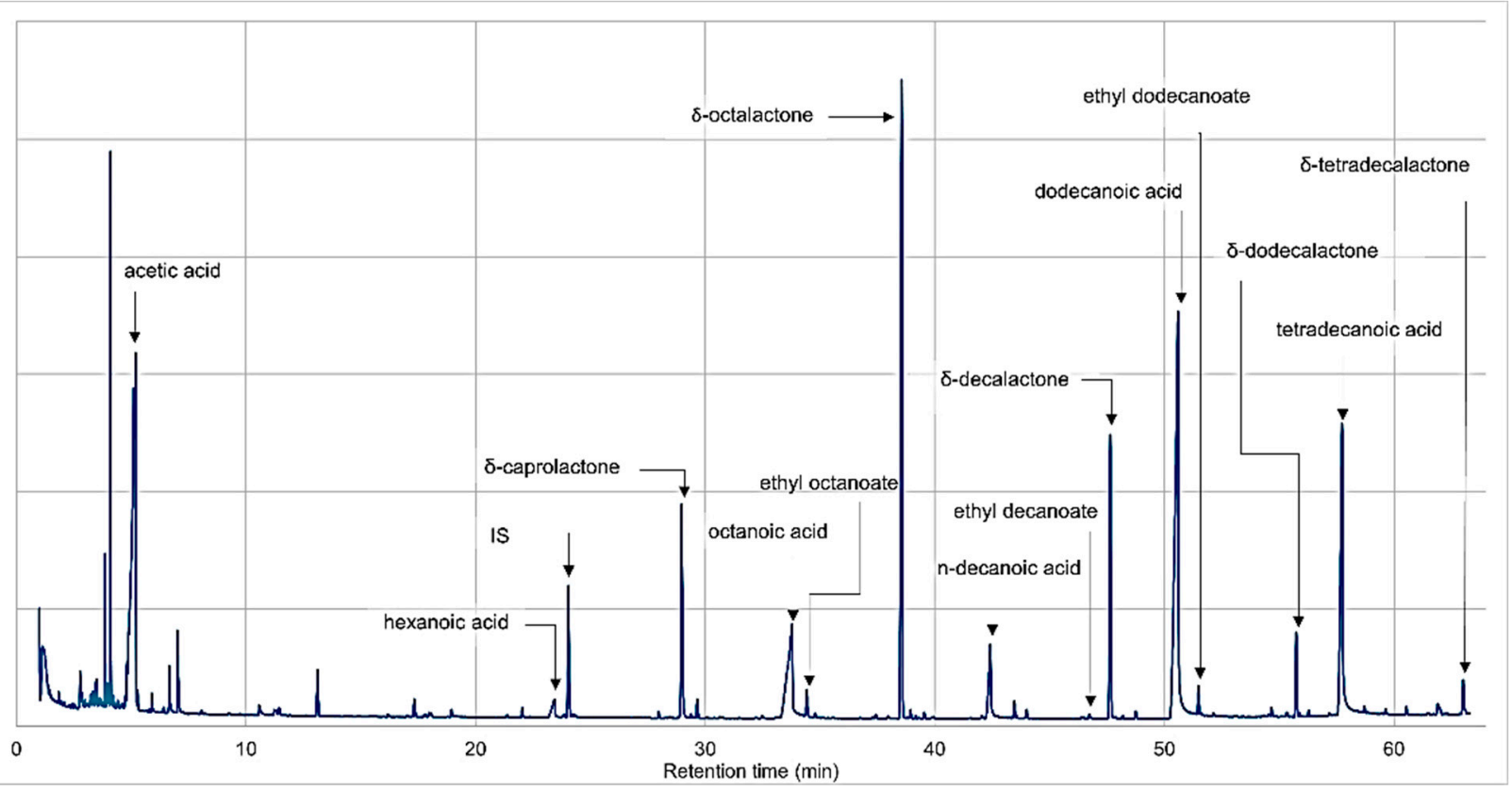

(a)

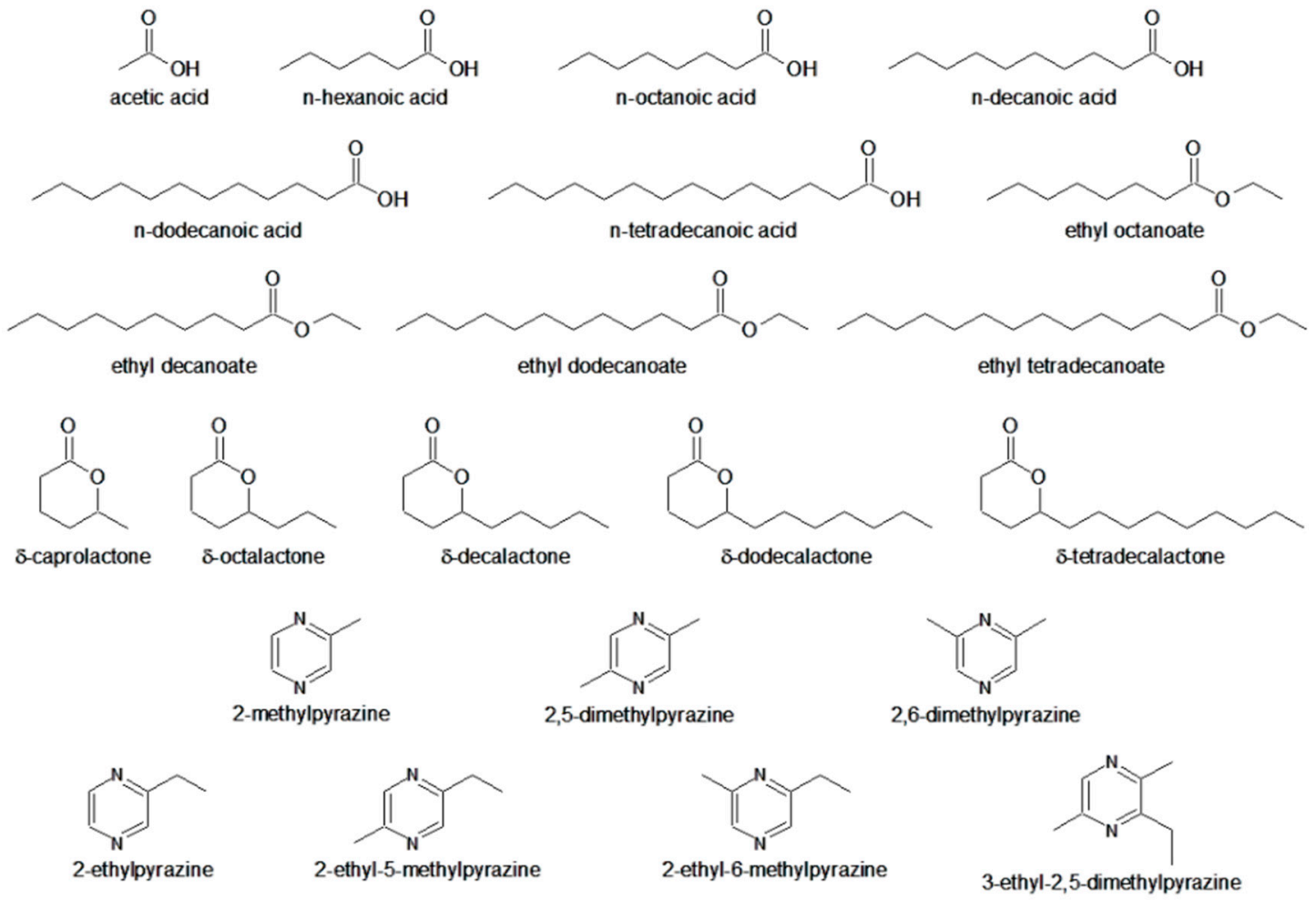

(b)

Figure 1. Major VOCs of VCO: (a) Sample GC-MS total ion chromatogram (TIC) of major VOCs (IS used was 2-octanol) of VCO produced by fermentation; and (b) chemical structures of VOCs detected from VCO samples.

Figure 2 shows the range of normalized areas of the major VOCs. The full listings of the VOCs in the different VCOs and RBDCOs are in Appendix A Tables A1-A4. The C6 to $\mathrm{C} 12$ delta-lactones, n-octanoic acid, n-dodecanoic acid, and acetic acid have high \%normalized areas. The rest of the major VOCs have intermediate \%normalized areas. It can 
be observed from Figure 2 that the values even within each process are significantly variable. For some compounds, there were samples with values that are outside the $\pm 1.5^{*} \mathrm{IQR}$ (interquartile range, represented by points outside the boxes of the boxplots). Most of the major VOCs were found in more than $80 \%$ of the VCO samples analyzed. A notable exception is ethyl tetradecanoate, which was found in only six samples (three fermentation (FER) and three expeller (EXP)). n-Hexanoic acid was the only major VOC found in the RBDCO samples, and only in two out of five samples.
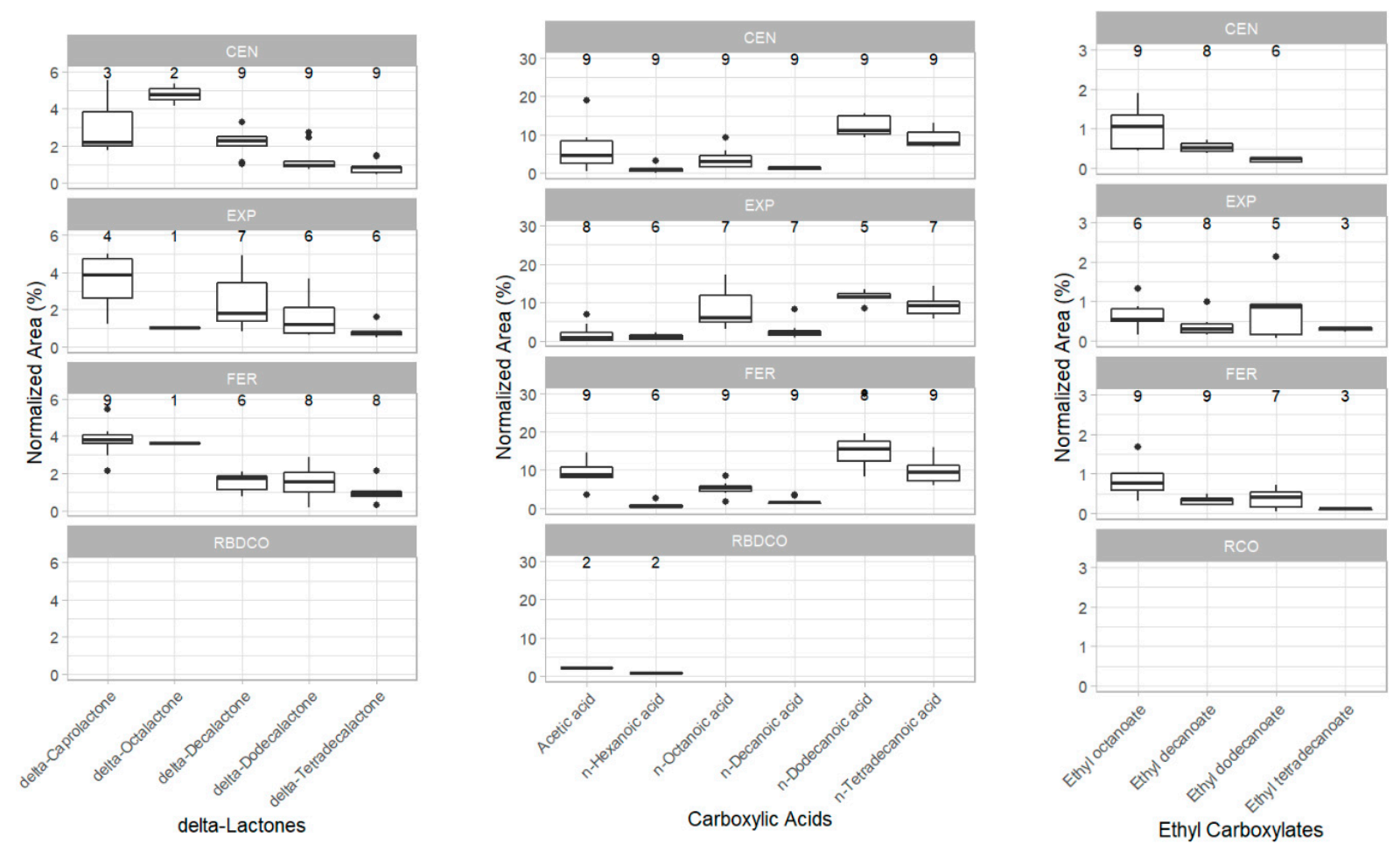

Figure 2. Range of relative amounts (based on normalized areas of the components in the GC-MS TIC) of the of the major VOCs in VCO from different processes (CEN, centrifugation; EXP, expeller; FER, fermentation) and of RBDCO (refined, bleached and deodorized coconut oil). The numbers on top of every box represent the number of times the particular VOC was detected. (The total number of samples per category is nine for CEN, EXP, and FER and five for RBDCO).

\subsection{Minor VOCs of VCOs and RBDCOs}

Figure 3 shows selected minor VOCs in VCO and RBDCO samples (see also Tables A1-A4). Aldehydes and ketones were detected in the headspaces of VCO and RBDCO samples. Butanal, hexanal, and nonanal were found in most of the RBDCOs but not 3hydroxy-butanone, 2-pentanone, and 2-heptanone. Pyrazines were detected in VCO samples produced by the expeller method. It must be noted that the \%normalized areas are not directly convertible to absolute concentrations. A high \%normalized area can be a result of a smaller number of components in a mixture. Hydrocarbons, such as n-hexane, toluene, and naphthalene, were also detected. Other alkanes and alkenes were detected in RBDCOs, more so in the old sample, and in some submitted VCO samples (see Table A8). 

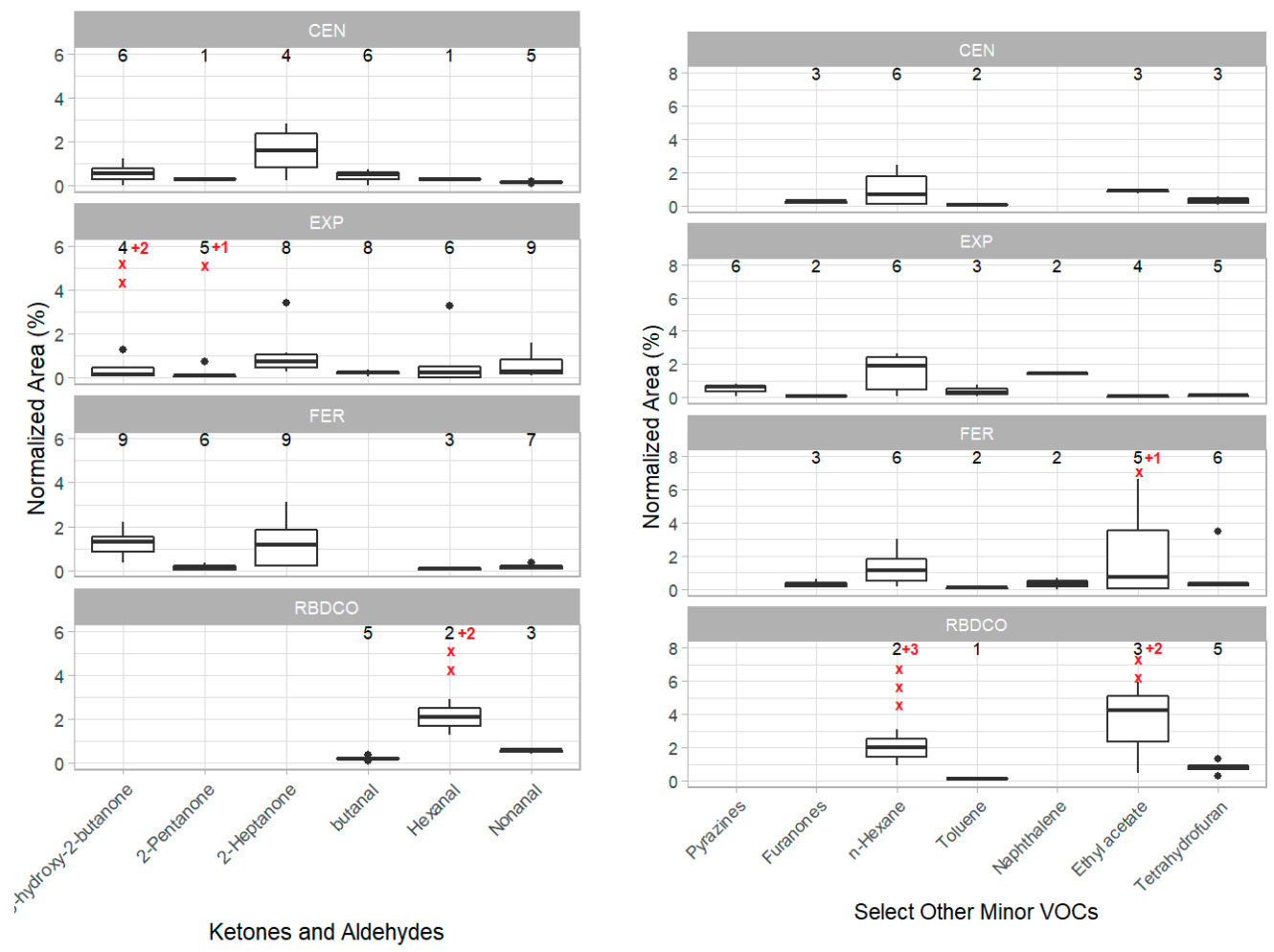

Figure 3. Range of relative amounts (based on normalized areas of the components in the GC-MS TIC) of the of selected minor VOCs in VCO from different processes (CEN, EXP, FER) and of RBDCO. The numbers on top of every box represent the number of times the particular VOC was detected. The total number of samples per category is nine for CEN, EXP and FER, and five for RBDCO. The $\times$ mark is a datapoint beyond the scale of the graph.

\subsection{PCA}

Principal component analysis (PCA) was done to examine the relationship between the method of VCO production and the detected VOCs. Figure 4 shows the scores plot of the first two principal components. The RBDCO samples are clearly separated from the VCO samples. VCO samples prepared by centrifugation are less variable and are more closely clustered together than those prepared by fermentation and expeller. The VCO from the expeller method showed high variability between methods used, while the VCO from the fermentation method showed high variability between methods and within the method (between batches).

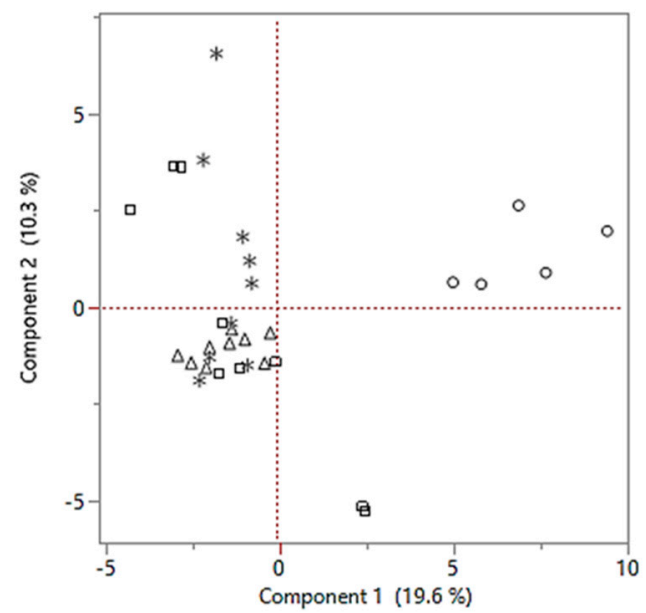

Figure 4. Scores plot of the first two components of the PCA of VOCs of VCO $(\triangle$ centrifugation; $\square$ expeller; * fermentation) and RBDCO (०) samples. 


\section{Discussion}

Among the major VOCs detected in this study, the C6 and C14 delta-lactones were not observed in earlier studies; there are now five delta-lactones that have been detected in VCO. Five fatty acids were observed, from C6 to C14. Only three of the ethyl carboxylates of these acids, C8, C10, and C12 were detected in very small quantities.

The major VOCs found in VCO samples originate from the coconut kernel. The different processes of VCO production can affect the amounts of these compounds in the VOC. In the wet methods, the amount of the major VOCs in oil is partly due to the partitioning behavior of the compounds between the aqueous and the oil layer. The partitioning of free fatty acids is further affected by the $\mathrm{pH}$ of the aqueous layer. The complexity of the fermentation process makes it difficult to control the final state of the aqueous layer, which results in the large variation in the VOC profiles even in samples prepared from the same method from different batches. This may explain the overlaps in the PCA profile. On the other hand, the centrifugation process produced more consistent VOC results with the least variability between methods and between batches. In the expeller method, the variability in the VOC profile can be attributed to the differences in the drying methods of different VCO manufacturers.

Fourteen major compounds were consistently present in freshly-prepared VCO samples but absent in RBDCOs, with the exception of hexanoic acid. Some of the minor VOCs may have developed during the production process. In the fermentation method, microbial action can lead to a wide range of organic products. Acetic acid is present in all samples but can be as low as $0.5 \%$ in abundance. The fermentation method produces more acetic acid up to $12 \%$ abundance; the amount of acetic acid also affects the free fatty acid level. Formic acid was also detected at $0-0.4 \%$, but as much as $2.7 \%$ in the old RBDCO (See Table A4). Because fermentation can also occur in coconut milk, fermentation products may also be detected in VCO produced from centrifugation. Minor VOCs detected in fermentation and centrifuge VCO included benzoic acid, butanoic acid, and pentadecanoic acid. On the other hand, the drying step makes the expeller method less prone to microbial and enzymatic action. However, the expeller method produces pyrazines from heating of the coconut meat. Ketones, in particular 3-hydroxy-2,3-butanone (acetoin) and 2-heptanone were detected in significant amounts in the expeller VCO, along with trace quantities of 2-pentadecanone and 2-undecanone. Hydrocarbons were also found in the samples, but more prominently in RBDCO. The 13-year-old RBDCO sample contained high concentrations of hydrocarbons, indicating that these compounds were produced during storage.

\section{Conclusions}

Fourteen major VOCs were detected in the headspace of VCO: Acetic acid; the fatty acids and the corresponding delta-lactones of $\mathrm{C} 6, \mathrm{C} 8, \mathrm{C} 10, \mathrm{C} 12$, and $\mathrm{C} 14$, and the ethyl carboxylates of $\mathrm{C} 8, \mathrm{C} 10$, and $\mathrm{C} 12$. Fourteen minor VOCs were likewise detected. These can be grouped into five types: Carboxylic acids (formic acid, butanoic acid, benzoic acid, and pentadecanoic acid), ketones (acetoin, 2-heptanone), an alcohol (ethanol), aldehydes (acetaldehyde, hexanal, benzaldehyde), esters (ethyl acetate, methyl tetradecanoate), and hydrocarbons (n-hexane and toluene). Five pyrazines were detected in the expeller VCO. Various hydrocarbons from C5 to C14 were noted to be higher in old RBDCO and VCO samples. The occurrence of these compounds in VCO samples prepared using different methods can suggest ways by which VCO processing can be improved.

Funding: This work was funded by the Philippine Council for Industry and Energy and Emerging Technologies Research and Development, Department of Science and Technology (PCIEERDDOST).

Institutional Review Board Statement: Not applicable.

Informed Consent Statement: Not applicable. 
Data Availability Statement: Additional data are given in the Appendix A.

Acknowledgments: We would like to thank the Virgin Coconut Oil Philippines and the Philippine Coconut Authority for their valuable help.

Conflicts of Interest: The authors declare no conflict of interest. The funders had no role in the design of the study; in the collection, analyses, or interpretation of data; in the writing of the manuscript, or in the decision to publish the results.

\section{Appendix A}

Table A1. Volatile organic compounds (VOCs) in VCO produced by fermentation method.

\begin{tabular}{|c|c|c|c|c|c|c|c|c|c|c|c|}
\hline & \multirow{2}{*}{ Volatile Compound } & \multirow{2}{*}{ Retention Time } & \multicolumn{9}{|c|}{ \%Area (Abundance) } \\
\hline & & & F1-0 & F1-1 & F1-2 & F2-0 & F2-1 & F2-2 & F3-0 & F3-1 & F3-2 \\
\hline 1 & Acetaldehyde & $3.9-4.1$ & - & - & 0.14 & - & - & 0.06 & & - & - \\
\hline 2 & Ethanol & $3.9-4.7$ & 1.18 & 1.36 & 2.94 & 0.50 & 0.48 & 2.65 & 3.18 & 2.36 & 1.10 \\
\hline 3 & Formic acid and esters & $4.2-16.0$ & 0.26 & 0.37 & - & - & 0.21 & 0.30 & 0.24 & 0.26 & 0.34 \\
\hline 4 & Acetic acid & $4.8-5.8$ & 8.85 & 8.03 & 10.69 & 10.26 & 8.22 & 12.31 & 14.46 & 7.85 & 3.58 \\
\hline 5 & n-Hexane & $4.7-5.3$ & - & 3.01 & 1.25 & 0.15 & 0.97 & 0.35 & - & - & 1.99 \\
\hline 6 & 2-Butanone, 3-hydroxy- & $4.9-7.6$ & 1.68 & 0.84 & 1.27 & 0.58 & 2.21 & 1.44 & 1.29 & 1.51 & 0.36 \\
\hline 7 & Ethyl Acetate & $5.0-5.3$ & 0.72 & 6.64 & 11.11 & - & - & 3.53 & - & 0.04 & 0.07 \\
\hline 8 & Tetrahydrofuran & $5.2-5.9$ & 0.46 & 0.21 & 0.28 & - & 0.13 & 3.50 & - & 0.26 & - \\
\hline 9 & 1-Butanol + isomer & $5.8-6.5$ & 0.21 & 0.11 & $0 . .21$ & - & 0.13 & 0.26 & - & 0.23 & - \\
\hline 10 & Butanal isomers & $5.6-5.8$ & - & - & - & - & - & - & - & - & - \\
\hline 11 & 2-Pentanone & $6.3-7.0$ & 0.35 & 0.01 & 0.04 & - & 0.08 & 0.03 & - & 0.26 & - \\
\hline 12 & Toluene & $9.1-9.3$ & - & 0.03 & - & - & 0.13 & - & - & - & - \\
\hline 13 & 2,3-Butanediol & $10.2-11.7$ & - & 0.09 & 0.13 & - & 0.80 & 0.40 & 0.57 & 1.06 & 0.38 \\
\hline 14 & Hexanal & $11.3-11.5$ & - & - & 0.05 & - & 0.17 & - & - & - & 0.06 \\
\hline 15 & Pyrazines & $12.7-23.9$ & - & - & - & - & - & - & - & - & - \\
\hline 16 & 2-Heptanone & $16.6-17.5$ & 3.13 & 0.21 & 0.28 & 1.22 & 1.84 & 0.23 & 0.15 & 3.00 & 1.15 \\
\hline 17 & Butanoic acid, 4-hydroxy- & 18.6 & - & - & - & - & 0.13 & 0.11 & - & - & - \\
\hline 18 & Benzaldehyde & $21.3-21.4$ & 0.12 & - & 0.03 & - & 0.84 & 0.15 & - & 0.08 & 0.20 \\
\hline 19 & Hexanoic acid & $23.3-23.8$ & - & - & 0.49 & 0.56 & 0.24 & - & 0.41 & 2.57 & 0.87 \\
\hline 20 & 2-Octanol (internal standard) & $23.9-24.1$ & 3.23 & 1.72 & 2.24 & 3.80 & 5.76 & 2.12 & 1.91 & 2.53 & 1.75 \\
\hline 21 & $\delta$-Caprolactone & $28.9-29.0$ & 4.26 & 2.98 & 4.07 & 3.79 & 2.12 & 3.61 & 3.77 & 5.46 & 3.94 \\
\hline 22 & Nonanal & $29.6-29.7$ & 0.04 & 0.06 & 0.17 & 0.20 & 0.19 & 0.14 & - & - & 0.35 \\
\hline 23 & 2(3H)-Furanones & $21.1-37.3$ & - & - & - & - & 0.60 & 0.19 & - & - & 0.16 \\
\hline 24 & Benzoic acid + isomers & $33.1-49.9$ & - & - & - & - & 0.81 & 3.21 & - & 0.45 & 0.53 \\
\hline 25 & Naphthalene and derivatives & $33.4-46.6$ & - & - & - & - & 0.66 & & - & - & - \\
\hline 26 & Octanoic acid & $33.4-34.5$ & 4.95 & 4.44 & 5.43 & 8.42 & 1.88 & 4.08 & 5.25 & 6.5 & 5.27 \\
\hline 27 & Octanoic acid, ethyl ester & $34.4-34.5$ & 0.58 & 0.31 & 0.50 & 1.67 & 0.75 & 1.00 & 0.82 & 1.01 & 0.64 \\
\hline 28 & $\delta$-Octalactone & $38.4-38.7$ & 15.14 & 11.61 & 14.42 & 8.96 & 3.58 & 9.61 & 7.31 & 11.60 & 10.78 \\
\hline 29 & 2-Undecanone & $38.9-39.0$ & - & 0.07 & 0.12 & 0.33 & 0.33 & 0.23 & - & 0.28 & 0.26 \\
\hline 30 & n-Decanoic acid & $42.2-42.8$ & 1.38 & 1.59 & 1.58 & 3.67 & 1.28 & 1.21 & 3.30 & 1.19 & 1.64 \\
\hline 31 & Decanoic acid, ethyl ester & $43.4-43.5$ & 0.34 & 0.20 & 0.29 & 0.49 & 0.21 & 0.40 & 0.23 & 0.37 & 0.33 \\
\hline 32 & $\delta$-Decalactone & $47.5-47.7$ & 8.31 & 6.31 & 6.67 & 2.09 & 0.76 & 1.72 & 0.93 & 1.71 & 1.89 \\
\hline 33 & Dodecanoic acid, methyl ester & $48.7-48.8$ & - & 0.10 & - & - & 0.07 & - & - & 0.36 & - \\
\hline 34 & Dodecanoic acid & $50.3-51.0$ & 13.73 & 19.65 & 15.53 & 29.89 & 15.52 & 8.57 & 33.41 & 8.40 & 16.68 \\
\hline 35 & Dodecanoic acid, ethyl ester & $51.4-51.5$ & 0.71 & 0.53 & 0.53 & 0.41 & 0.04 & 0.17 & - & 0.14 & - \\
\hline 36 & -Dodecalactone & $54.2-54.7$ & - & - & - & 0.15 & 3.33 & 1.75 & - & 1.38 & 1.23 \\
\hline 37 & $\delta$-Dodecalactone & $55.6-55.8$ & 2.39 & 1.93 & 1.84 & 0.66 & 2.86 & - & 0.29 & 1.20 & 1.08 \\
\hline 38 & Methyl tetradecanoate & 56.3 & - & 0.10 & - & - & - & - & - & - & - \\
\hline 39 & Tetradecanoic acid & $57.5-57.9$ & 7.51 & 15.91 & 10.45 & 9.32 & 7.13 & 5.99 & 11.22 & 6.09 & 11.25 \\
\hline 40 & Tetradecanoic acid, ethyl ester & $58.7-58.8$ & 0.10 & 0.12 & 0.08 & - & - & - & - & - & - \\
\hline 41 & Pentadecanoic acid & $61.0-61.1$ & - & - & - & - & - & - & - & 3.74 & 0.90 \\
\hline 42 & $\delta$-Tetradecalactone & $62.9-63.1$ & 0.75 & 0.82 & 0.73 & 0.30 & 2.12 & 0.95 & - & 1.09 & 0.99 \\
\hline
\end{tabular}


Table A2. VOCs in VCO produced by centrifuge method.

\begin{tabular}{|c|c|c|c|c|c|c|c|c|c|c|c|}
\hline & \multirow{2}{*}{ Volatile Compound } & \multirow{2}{*}{ Retention Time } & \multicolumn{9}{|c|}{ \%Area (Abundance) } \\
\hline & & & C1-0 & C1-1 & C1-2 & $\mathrm{C} 2-0$ & C2-1 & $\mathrm{C} 2-2$ & C3-0 & C3-1 & C3-2 \\
\hline 1 & Acetaldehyde & $3.9-4.1$ & - & - & & - & - & - & - & - & - \\
\hline 2 & Ethanol & $3.9-4.7$ & 0.68 & 1.15 & 0.86 & 0.54 & 3.94 & 1.10 & 0.95 & 3.49 & 3.41 \\
\hline 3 & Formic acid & $4.2-5.0$ & - & 0.29 & - & - & 0.15 & 0.26 & 0.36 & 0.23 & 0.18 \\
\hline 4 & Acetic acid & $4.8-5.8$ & 8.43 & 4.08 & - & 2.52 & 9.33 & 4.43 & 18.94 & 0.67 & 0.46 \\
\hline 5 & n-Hexane & $4.7-5.3$ & - & 1.98 & - & 2.45 & 1.13 & 0.09 & - & 0.10 & 0.22 \\
\hline 6 & 2-Butanone, 3-hydroxy- & $4.9-7.6$ & - & 0.48 & 0.24 & - & 1.25 & 0.81 & 0.64 & 0.02 & - \\
\hline 7 & Ethyl Acetate & $5.0-5.3$ & - & 0.76 & 0.95 & - & - & 0.93 & - & - & - \\
\hline 8 & Tetrahydrofuran & $5.2-5.9$ & - & 0.58 & 0.45 & 0.73 & 0.59 & - & 0.24 & - & 0.03 \\
\hline 9 & 1-Butanol & $5.8-6.5$ & 0.48 & 0.09 & 0.16 & - & 0.26 & 0.09 & - & 0.16 & 0.15 \\
\hline 10 & Butanal isomers & $5.6-5.8$ & - & - & - & - & 0.06 & - & - & - & 0.02 \\
\hline 11 & 2-Pentanone & $6.3-7.0$ & - & - & - & - & 0.28 & - & - & - & - \\
\hline 12 & Toluene & $9.1-9.3$ & 0.57 & 0.06 & - & 0.30 & - & - & - & - & - \\
\hline 13 & 2,3-Butanediol & $10.2-11.7$ & - & - & - & 0.57 & 0.17 & 0.12 & 1.23 & 0.10 & - \\
\hline 14 & Hexanal & $11.3-11.5$ & - & - & - & - & - & 0.27 & - & - & - \\
\hline 15 & Pyrazines & $12.7-23.9$ & - & - & - & - & - & - & - & - & - \\
\hline 16 & 2-Heptanone & $16.6-17.5$ & - & - & - & 2.83 & 2.19 & 1.01 & 0.24 & - & - \\
\hline 17 & Butanoic acid, 4-hydroxy- & 18.6 & - & - & - & 0.24 & - & - & - & 0.19 & 0.19 \\
\hline 18 & Benzaldehyde & $21.3-21.4$ & 0.37 & 0.32 & 0.28 & 0.30 & 0.25 & 0.25 & 0.24 & 0.19 & 0.18 \\
\hline 19 & Hexanoic acid & $23.3-23.8$ & 0.88 & 0.54 & 0.83 & 3.28 & 0.83 & 1.07 & 1.21 & 0.14 & 0.18 \\
\hline 20 & 2-Octanol (internal standard) & $23.9-24.1$ & 2.19 & 2.71 & 3.71 & 3.26 & 3.05 & 3.09 & 2.23 & 2.53 & 2.41 \\
\hline 21 & $\delta$-Caprolactone & $28.9-29.0$ & 9.80 & 5.51 & 6.74 & 9.75 & 7.94 & 7.69 & 7.70 & 1.77 & 2.19 \\
\hline 22 & Nonanal & $29.6-29.7$ & 0.17 & 0.21 & - & - & - & - & 0.11 & 0.15 & 0.16 \\
\hline 23 & 2(3H)-Furanones & $21.1-37.3$ & - & - & - & - & - & 0.09 & - & 0.29 & 0.26 \\
\hline 24 & Benzoic acid + isomers & $33.1-49.9$ & 4.71 & 5.14 & 5.98 & 3.95 & 3.14 & 3.85 & 2.94 & 4.40 & 2.92 \\
\hline 25 & Naphthalene & 33.4 & - & - & - & - & - & - & - & - & - \\
\hline 26 & Octanoic acid & $33.4-34.5$ & 2.86 & 1.77 & 1.71 & 9.32 & 4.08 & 5.80 & 4.51 & 1.38 & 1.49 \\
\hline 27 & Octanoic acid, ethyl ester & $34.4-34.5$ & 0.48 & 0.44 & 0.51 & 0.50 & 1.83 & 1.91 & 1.04 & 1.14 & 1.33 \\
\hline 28 & o-Octalactone & $38.4-38.7$ & 23.57 & 18.35 & 19.77 & 18.89 & 17.90 & 16.64 & 15.35 & 4.16 & 5.35 \\
\hline 29 & 2-Undecanone & $38.9-39.0$ & - & 0.13 & - & 0.53 & 0.77 & 0.40 & - & 0.27 & 0.24 \\
\hline 30 & n-Decanoic acid & $42.2-42.8$ & 1.01 & 1.11 & 1.14 & 1.51 & 1.01 & 1.6 & 0.96 & 1.67 & 1.67 \\
\hline 31 & Decanoic acid, ethyl ester & $43.4-43.5$ & 0.37 & 0.39 & 0.43 & - & 0.58 & 0.63 & 0.42 & 0.61 & 0.72 \\
\hline 32 & $\delta$-Decalactone & $47.5-47.7$ & 3.26 & 2.39 & 2.27 & 2.49 & 2.23 & 2.49 & 2.01 & 1.05 & 1.13 \\
\hline 33 & Dodecanoic acid, methyl ester & $48.7-48.8$ & - & - & - & - & - & - & - & 0.10 & 0.09 \\
\hline 34 & Dodecanoic acid & $50.3-51.0$ & 11.13 & 14.25 & 15.47 & 9.92 & 10.83 & 10.26 & 9.37 & 15.10 & 14.90 \\
\hline 35 & Dodecanoic acid, ethyl ester & $51.4-51.5$ & - & 0.14 & 0.13 & - & 0.23 & 0.25 & - & 0.27 & 0.28 \\
\hline 36 & $\mathrm{\gamma}$-Dodecalactone & $54.2-54.7$ & 1.10 & 1.43 & 1.54 & 1.09 & 1.18 & 1.19 & 1.10 & 3.66 & 2.76 \\
\hline 37 & $\delta$-Dodecalactone & $55.6-55.8$ & 0.88 & 1.17 & 1.10 & 0.75 & 0.89 & 0.93 & 0.90 & 2.73 & 2.45 \\
\hline 38 & Methyl tetradecanoate & 56.3 & - & - & - & - & - & - & - & 0.28 & - \\
\hline 39 & Tetradecanoic acid & $57.5-57.9$ & 7.53 & 9.75 & 10.70 & 6.83 & 7.34 & 7.63 & 7.06 & 13.05 & 11.31 \\
\hline 40 & Tetradecanoic acid, ethyl ester & $58.7-58.8$ & - & - & - & - & - & - & - & - & - \\
\hline 41 & Pentadecanoic acid & $61.0-61.1$ & - & - & 0.36 & 0.34 & 0.29 & 0.47 & 0.25 & 1.12 & 1.29 \\
\hline 42 & $\delta$-Tetradecalactone & $62.9-63.1$ & 0.54 & 0.84 & 0.88 & 0.50 & 0.61 & 0.55 & 0.89 & 1.45 & 1.51 \\
\hline
\end{tabular}

Table A3. VOCs in VCO produced by expeller method.

\begin{tabular}{|c|c|c|c|c|c|c|c|c|c|c|c|}
\hline & \multirow{2}{*}{ Volatile Compound } & \multirow{2}{*}{ Retention Time } & \multicolumn{9}{|c|}{ \%Area (Abundance) } \\
\hline & & & E1-0 & E1-1 & E1-2 & E2-0 & E2-1 & E2-2 & E3-0 & E3-1 & E3-2 \\
\hline 1 & Acetaldehyde & $3.9-4.1$ & 0.14 & 0.09 & - & - & 0.06 & 0.20 & - & 0.13 & 0.25 \\
\hline 2 & Ethanol & $3.9-4.7$ & 0.51 & 0.17 & 0.02 & 0.43 & 0.25 & 0.28 & - & 2.46 & 0.91 \\
\hline 3 & Formic acid & $4.2-5.0$ & 0.24 & 0.12 & - & 2.14 & 0.07 & - & - & - & - \\
\hline 4 & Acetic acid & $4.8-5.8$ & 0.38 & 0.26 & 0.05 & 4.31 & 0.08 & - & 6.82 & 1.22 & 1.39 \\
\hline 5 & n-Hexane & $4.7-5.3$ & - & 0.09 & 0.05 & 2.68 & 1.58 & - & - & 2.46 & 2.21 \\
\hline 6 & 2-Butanone, 3-hydroxy- & $4.9-7.6$ & - & 0.10 & - & 1.30 & 0.06 & 0.18 & - & 6.53 & 23.19 \\
\hline 7 & Ethyl Acetate & $5.0-5.3$ & - & 0.03 & 0.07 & - & - & - & - & 0.13 & 0.02 \\
\hline 8 & Tetrahydrofuran & $5.2-5.9$ & 0.07 & 0.27 & 0.10 & 0.24 & 0.30 & 0.37 & - & 0.27 & 0.22 \\
\hline 9 & 1-Butanol & $5.8-6.5$ & - & 0.02 & - & - & - & 0.06 & - & - & 0.71 \\
\hline 10 & Butanal isomers & $5.6-5.8$ & - & 0.05 & - & - & - & - & - & 0.79 & 0.29 \\
\hline 11 & 2-Pentanone & $6.3-7.0$ & 0.06 & 0.09 & 0.03 & - & 0.75 & 0.09 & - & - & - \\
\hline 12 & Toluene & $9.1-9.3$ & 0.15 & 0.07 & 0.01 & - & - & - & - & 0.24 & 0.12 \\
\hline 13 & 2,3-Butanediol & $10.2-11.7$ & - & - & - & 1.24 & 0.80 & 3.40 & 8.31 & 20.23 & 23.79 \\
\hline
\end{tabular}




\begin{tabular}{|c|c|c|c|c|c|c|c|c|c|c|c|}
\hline 14 & Hexanal & $11.3-11.5$ & 0.05 & 0.04 & 0.03 & 3.29 & - & - & - & 0.43 & 0.55 \\
\hline 15 & Pyrazines & $12.7-23.9$ & 0.10 & 0.74 & - & - & 0.69 & 0.29 & - & 0.83 & 0.63 \\
\hline 16 & 2-Heptanone & $16.6-17.5$ & 0.80 & 1.04 & 0.29 & 3.41 & 12.06 & 1.15 & 0.71 & 0.27 & 0.55 \\
\hline 17 & Butanoic acid, 4-hydroxy- & 18.6 & - & - & - & 0.22 & 0.07 & 0.14 & - & 0.30 & 0.04 \\
\hline 18 & Benzaldehyde & $21.3-21.4$ & 0.10 & 0.09 & - & - & 0.12 & 0.25 & - & 0.21 & 0.16 \\
\hline 19 & Hexanoic acid & $23.3-23.8$ & 0.34 & 0.08 & 0.63 & 2.06 & 1.70 & 1.21 & - & - & - \\
\hline 20 & 2-Octanol (internal standard) & $23.9-24.1$ & 1.84 & 5.72 & 0.99 & 1.99 & 1.92 & 3.13 & 4.82 & 7.36 & 8.07 \\
\hline 21 & $\delta$-Caprolactone & $28.9-29.0$ & 3.07 & 4.66 & 1.22 & 6.89 & 5.01 & 9.59 & 17.14 & 10.04 & 8.50 \\
\hline 22 & Nonanal & $29.6-29.7$ & 0.27 & 0.29 & 0.09 & 0.41 & 0.14 & 0.21 & 0.82 & 1.60 & 1.61 \\
\hline 23 & 2(3H)-Furanones & $21.1-37.3$ & 0.07 & - & - & - & 0.07 & - & - & - & - \\
\hline 24 & Benzoic acid + isomers & $33.1-49.9$ & - & - & - & - & - & - & - & - & - \\
\hline 25 & Naphthalene & 33.4 & - & - & - & 1.39 & - & 1.51 & - & - & - \\
\hline 26 & Octanoic acid & $33.4-34.5$ & 6.00 & 3.05 & 17.27 & 8.34 & 15.49 & 5.70 & 4.14 & - & - \\
\hline 27 & Octanoic acid, ethyl ester & $34.4-34.5$ & 0.50 & 1.31 & - & 0.48 & 0.16 & 0.57 & - & 0.87 & 0.99 \\
\hline 28 & $\delta$-Octalactone & $38.4-38.7$ & 14.06 & 22.77 & 7.67 & 12.31 & 10.59 & 20.47 & 30.55 & 14.43 & 13.32 \\
\hline 29 & 2-Undecanone & $38.9-39.0$ & 0.32 & 0.53 & 0.11 & 0.49 & 0.43 & 0.67 & 0.83 & - & - \\
\hline 30 & n-Decanoic acid & $42.2-42.8$ & 3.21 & 1.82 & 8.30 & 1.52 & 1.89 & 1.38 & 0.85 & - & - \\
\hline 31 & Decanoic acid, ethyl ester & $43.4-43.5$ & 0.33 & 0.98 & 0.41 & 0.25 & 0.15 & 0.47 & - & 0.17 & 0.21 \\
\hline 32 & $\delta$-Decalactone & $47.5-47.7$ & 7.86 & 13.90 & 4.93 & 1.80 & 1.67 & 2.76 & 4.10 & 1.06 & 0.82 \\
\hline 33 & Dodecanoic acid, methyl ester & $48.7-48.8$ & 0.44 & 0.25 & 0.04 & - & 0.53 & - & - & 0.17 & 0.16 \\
\hline 34 & Dodecanoic acid & $50.3-51.0$ & 30.56 & 13.31 & 37.25 & 11.18 & 11.40 & 12.32 & 8.35 & - & - \\
\hline 35 & Dodecanoic acid, ethyl ester & $51.4-51.5$ & 0.91 & 2.13 & 0.84 & - & 0.06 & 0.16 & - & - & - \\
\hline 36 & y-Dodecalactone & $54.2-54.7$ & 0.25 & 0.17 & 0.03 & 0.86 & 0.79 & 0.62 & - & - & - \\
\hline 37 & $\delta$-Dodecalactone & $55.6-55.8$ & 2.31 & 3.65 & 1.58 & 0.74 & 0.66 & 0.80 & - & - & - \\
\hline 38 & Methyl tetradecanoate & 56.3 & 0.49 & 0.21 & 0.03 & - & - & - & - & - & - \\
\hline 39 & Tetradecanoic acid & $57.5-57.9$ & 10.95 & 6.10 & 14.39 & 9.06 & 8.30 & 9.50 & 5.71 & - & - \\
\hline 40 & Tetradecanoic acid, ethyl ester & $58.7-58.8$ & 0.22 & 0.35 & 0.30 & - & - & - & - & - & - \\
\hline 41 & Pentadecanoic acid & $61.0-61.1$ & 0.09 & - & - & 1.11 & 0.89 & 0.75 & - & - & - \\
\hline 42 & $\delta$-Tetradecalactone & $62.9-63.1$ & 0.86 & 1.60 & 0.69 & 0.73 & 0.49 & 0.62 & - & - & - \\
\hline
\end{tabular}

Table A4. VOCs in refined, bleached, and deodorized coconut oil (RBDCO).

\begin{tabular}{|c|c|c|c|c|c|c|c|c|}
\hline & \multirow{2}{*}{ Volatiles } & \multirow{2}{*}{ Retention Time } & \multicolumn{6}{|c|}{$\%$ Area (Abundance) } \\
\hline & & & RCO-1 & RCO-2 & RCO-3 & RCO-4 & RCO-5 & Old RCO \\
\hline 1 & Acetaldehyde & $3.9-4.1$ & 0.18 & 0.57 & 0.66 & 2.25 & 1.47 & 0.13 \\
\hline 2 & Ethanol & $3.9-4.7$ & 0.33 & 0.86 & 1.18 & 2.26 & 0.45 & 0.21 \\
\hline 3 & Formic acid & $4.2-5.0$ & - & - & - & - & - & 2.73 \\
\hline 4 & Acetic acid & $4.8-5.8$ & 4.16 & 2.10 & 3.06 & 0.84 & 2.18 & 1.22 \\
\hline 5 & n-Hexane & $4.7-5.3$ & 0.91 & 9.41 & 16.20 & 12.34 & 3.10 & 3.17 \\
\hline 6 & 2-Butanone, 3-hydroxy- & $4.9-7.6$ & - & - & - & - & - & - \\
\hline 7 & Ethyl Acetate & $5.0-5.3$ & 5.94 & 14.99 & 26.82 & 4.25 & 0.44 & 0.56 \\
\hline 8 & Tetrahydrofuran & $5.2-5.9$ & 0.37 & 0.21 & 0.11 & 0.18 & 0.18 & 0.24 \\
\hline 9 & 1-Butanol & $5.8-6.5$ & 0.14 & 0.08 & - & - & 0.20 & - \\
\hline 10 & Butanal isomers & $5.6-5.8$ & - & 0.13 & - & - & - & - \\
\hline 11 & 2-Pentanone & $6.3-7.0$ & - & - & - & - & - & 0.05 \\
\hline 12 & Toluene & $9.1-9.3$ & 0.88 & 0.72 & 1.32 & 0.93 & 0.28 & 3.39 \\
\hline 13 & 2,3-Butanediol & $10.2-11.7$ & - & - & - & - & - & - \\
\hline 14 & Hexanal & $11.3-11.5$ & 1.28 & 2.91 & 9.95 & 11.27 & 12.56 & 50.99 \\
\hline 15 & Pyrazines & $12.7-23.9$ & - & - & - & - & - & - \\
\hline 16 & 2-Heptanone & $16.6-17.5$ & - & - & - & - & - & 0.34 \\
\hline 17 & Butanoic acid isomers & 18.6 & 0.03 & - & - & - & - & - \\
\hline 18 & Benzaldehyde & $21.3-21.4$ & 0.42 & - & - & - & - & - \\
\hline 19 & Hexanoic acid & $23.3-23.8$ & - & 0.75 & - & - & 0.66 & 2.22 \\
\hline 20 & 2-Octanol (internal standard) & $23.9-24.1$ & 4.65 & 24.67 & 15.73 & 22.42 & 22.13 & 7.99 \\
\hline 21 & $\delta$-Caprolactone & $28.9-29.0$ & - & - & - & - & - & - \\
\hline 22 & Nonanal & $29.6-29.7$ & 0.61 & - & - & 0.40 & 0.59 & 0.66 \\
\hline 23 & 2(3H)-Furanones & $21.1-37.3$ & - & - & - & - & - & - \\
\hline 24 & Benzoic acid + isomers & $33.1-49.9$ & - & - & - & - & - & - \\
\hline 25 & Naphthalene & 33.4 & - & - & - & - & - & - \\
\hline 26 & Octanoic acid & $33.4-34.5$ & - & - & - & - & - & 2.58 \\
\hline 27 & Octanoic acid, ethyl ester & $34.4-34.5$ & - & - & - & - & - & - \\
\hline 28 & $\delta$-Octalactone & $38.4-38.7$ & - & - & - & - & - & - \\
\hline 29 & 2-Undecanone & $38.9-39.0$ & - & - & - & - & - & - \\
\hline 30 & n-Decanoic acid & $42.2-42.8$ & - & - & - & - & - & - \\
\hline
\end{tabular}


Decanoic acid, ethyl ester $\delta$-Decalactone

Dodecanoic acid, methyl ester Dodecanoic acid

Dodecanoic acid, ethyl ester $\gamma$-Dodecalactone $\delta$-Dodecalactone

Methyl tetradecanoate Tetradecanoic acid

Tetradecanoic acid, ethyl ester Pentadecanoic acid $\delta$-Tetradecalactone
43.4-43.5

$47.5-47.7$

$48.7-48.8$

$50.3-51.0$

51.4-51.5

54.2-54.7

$55.6-55.8$

56.3

$57.5-57.9$

$58.7-58.8$

61.0-61.1

62.9-63.1

Table A5. Hydrocarbon VOCs in VCOs produced by fermentation methods.

\begin{tabular}{|c|c|c|c|c|c|c|c|c|c|c|c|}
\hline & Hydrocarbon & Retention Time & F1-0 & F1-1 & F1-2 & F2-0 & F2-1 & F2-2 & F3-0 & F3-1 & F3-2 \\
\hline 1 & Butane + isomers & 4.2 & - & - & - & - & - & - & - & - & - \\
\hline 2 & Pentane + isomers & $4.6-6.1$ & - & - & - & - & 0.01 & - & - & - & - \\
\hline 3 & Hexane + isomers & $4.7-12.6$ & 1.80 & 3.01 & 1.25 & 0.15 & 0.97 & 0.36 & - & - & 1.99 \\
\hline 4 & Cyclopentane, methyl- & 5.3 & - & - & - & - & - & - & - & - & - \\
\hline 5 & Benzene + isomers & $5.7-47.2$ & 5.56 & 0.02 & 0.02 & - & 0.04 & - & - & - & - \\
\hline 6 & Heptane/heptene + isomers & $6.3-6.8$ & 0.64 & 0.04 & - & - & 0.02 & - & - & - & - \\
\hline 7 & Toluene & $9.11-9.3$ & - & - & - & - & 0.13 & - & - & - & 0.06 \\
\hline 8 & 1-Octene/octane + isomers & $10.7-21.6$ & 0.97 & - & - & - & - & - & - & - & - \\
\hline 9 & p-Xylene & $15.6-17.1$ & - & - & - & - & - & - & - & - & - \\
\hline 10 & Styrene & 16.9 & - & - & - & - & - & - & - & - & - \\
\hline 11 & Undecane + isomers & $21.7-23.8$ & 0.87 & 0.02 & 0.04 & 0.39 & - & 0.15 & - & - & - \\
\hline 12 & Nonane + isomers & $22.4-38.3$ & 3.13 & - & - & 1.35 & 0.55 & - & - & - & - \\
\hline 13 & 2-Octanol (Internal Standard) & 24.0 & 3.23 & 1.72 & 2.24 & 3.8 & 5.76 & 2.12 & 1.91 & 2.53 & 1.75 \\
\hline 14 & Decane + isomers & $25.1-37.5$ & - & - & - & 0.79 & 0.03 & - & - & - & - \\
\hline 15 & D-Limonene & 25.3 & - & - & - & - & - & - & - & - & - \\
\hline 16 & Dodecane + isomers & $27.0-35.5$ & 2.40 & - & - & 0.14 & 0.10 & - & - & - & - \\
\hline 17 & Naphthalene and derivatives & $33.4-53.6$ & - & - & - & & 0.15 & - & - & - & 0.42 \\
\hline 18 & Dodecane & 34.4 & - & - & - & - & - & - & - & - & - \\
\hline 19 & Hexadecane & 34.6 & - & - & - & 0.08 & 0.08 & 0.02 & - & - & - \\
\hline 20 & Tetradecane + isomers & $36.5-43.6$ & 0.05 & - & 0.04 & 0.32 & - & - & - & - & - \\
\hline 21 & Eicosane & $38.2-47.3$ & 0.27 & 0.03 & - & 0.46 & - & - & - & - & 0.70 \\
\hline \multirow[t]{2}{*}{22} & Heneicosane & $47.1-49.2$ & - & - & - & - & 0.18 & 0.03 & - & - & 0.16 \\
\hline & Total \%Normalized Area & & 15.69 & 3.12 & 1.35 & 3.68 & 2.26 & 0.56 & 0.00 & 0.00 & 3.33 \\
\hline
\end{tabular}

Table A6. Hydrocarbon VOCs in VCOs produced by centrifuge methods.

\begin{tabular}{|c|c|c|c|c|c|c|c|c|c|c|c|}
\hline & Hydrocarbon & Retention Time & C1-0 & C1-1 & C1-2 & $\mathrm{C} 2-0$ & C2-1 & $\mathrm{C} 2-2$ & C3-0 & C3-1 & C3-2 \\
\hline 1 & Butane + isomers & 4.2 & - & - & - & 0.38 & - & - & - & - & - \\
\hline 2 & Pentane + isomers & $4.6-6.1$ & - & - & - & - & 0.05 & 0.38 & - & - & - \\
\hline 3 & Hexane + isomers & $4.7-12.6$ & - & 1.98 & - & 2.45 & 1.13 & 0.09 & & 0.10 & 0.22 \\
\hline 4 & Cyclopentane, methyl- & 5.3 & - & - & - & - & - & - & - & - & - \\
\hline 5 & Benzene + isomers & $5.7-47.2$ & - & - & - & - & - & - & - & - & - \\
\hline 6 & Heptane/heptene + isomers & $6.3-6.8$ & 0.76 & - & - & 1.14 & - & - & - & - & - \\
\hline 7 & Toluene & $9.11-9.3$ & 0.57 & - & - & 0.3 & - & - & - & - & - \\
\hline 8 & 1-Octene/octane + isomers & $10.7-21.6$ & - & - & - & - & - & - & - & - & - \\
\hline 9 & p-Xylene & $15.6-17.1$ & - & - & - & - & - & - & - & - & - \\
\hline 10 & Styrene & 16.9 & - & - & - & - & - & - & - & - & - \\
\hline 11 & Undecane + isomers & $21.7-23.8$ & - & - & - & - & - & - & - & - & - \\
\hline 12 & Nonane + isomers & $22.4-38.3$ & 0.83 & - & - & 0.31 & - & - & 0.59 & - & - \\
\hline 13 & 2-Octanol (Internal Standard) & 24.0 & 2.19 & 2.71 & 3.71 & 3.26 & 3.05 & 3.09 & 2.23 & 2.53 & 2.43 \\
\hline 14 & Decane + isomers & $25.1-37.5$ & - & - & - & - & - & - & - & - & - \\
\hline 15 & D-Limonene & 25.3 & - & - & - & - & - & - & - & - & - \\
\hline 16 & Dodecane + isomers & $27.0-35.5$ & - & - & - & - & - & - & - & - & - \\
\hline 17 & Naphthalene and derivatives & $33.4-53.6$ & - & - & - & - & - & - & - & - & - \\
\hline 18 & Dodecane & 34.4 & - & - & - & - & - & - & - & - & - \\
\hline 19 & Hexadecane & 34.6 & - & - & - & - & - & - & - & - & - \\
\hline 20 & Tetradecane + isomers & $36.5-43.6$ & - & - & - & - & - & - & - & - & - \\
\hline 21 & Eicosane & $38.2-47.3$ & 0.48 & - & - & 0.4 & - & - & 0.33 & - & - \\
\hline
\end{tabular}


Table A7. Hydrocarbon VOCs detected in VCOs produced by expeller method.

\begin{tabular}{|c|c|c|c|c|c|c|c|c|c|c|c|}
\hline & Hydrocarbon & Retention Time & E1-0 & E1-1 & E1-2 & E2-0 & E2-1 & E2-2 & E3-0 & E3-1 & $\overline{\text { E3-2 }}$ \\
\hline 1 & Butane + isomers & 4.2 & - & - & - & - & - & - & - & - & - \\
\hline 2 & Pentane + isomers & $4.6-6.1$ & - & - & - & - & - & 0.04 & - & - & - \\
\hline 3 & Hexane + isomers & $4.7-12.6$ & 0.09 & - & - & 2.68 & 1.58 & - & - & 2.46 & 2.21 \\
\hline 4 & Cyclopentane, methyl- & 5.3 & - & - & - & - & - & - & - & - & - \\
\hline 5 & Benzene + isomers & $5.7-47.2$ & 0.14 & - & - & - & 0.02 & 0.04 & - & 0.13 & - \\
\hline 6 & Heptane/heptene + isomers & $6.3-6.8$ & 0.58 & - & - & - & - & - & 0.91 & 0.39 & - \\
\hline 7 & Toluene & $9.11-9.3$ & 0.15 & - & - & - & - & - & - & 0.24 & 0.12 \\
\hline 8 & 1-Octene/octane + isomers & $10.7-21.6$ & & - & - & - & - & - & - & - & 0.05 \\
\hline 9 & p-Xylene & $15.6-17.1$ & - & - & - & - & - & - & - & - & - \\
\hline 10 & Styrene & 16.9 & - & - & - & - & - & - & - & 0.13 & - \\
\hline 11 & Undecane + isomers & $21.7-23.8$ & 0.14 & - & - & - & - & - & - & - & - \\
\hline 12 & Nonane + isomers & $22.4-38.3$ & 0.19 & - & - & - & - & - & - & - & - \\
\hline 13 & 2-Octanol (Internal Standard) & 24.0 & 1.84 & 5.72 & 0.99 & 1.99 & 1.92 & 3.13 & 4.82 & 7.36 & 8.07 \\
\hline 14 & Decane + isomers & $25.1-37.5$ & 0.26 & - & - & - & - & - & - & - & - \\
\hline 15 & D-Limonene & 25.3 & - & - & - & - & - & - & - & - & - \\
\hline 16 & Dodecane + isomers & $27.0-35.5$ & - & - & - & - & - & - & - & - & - \\
\hline 17 & Naphthalene and derivatives & $33.4-53.6$ & - & - & - & 1.39 & - & 1.51 & - & - & - \\
\hline 18 & Dodecane & 34.4 & - & - & - & - & - & - & - & - & - \\
\hline 19 & Hexadecane & 34.6 & - & - & - & - & - & - & - & - & - \\
\hline 20 & Tetradecane + isomers & $36.5-43.6$ & 0.12 & - & - & - & - & - & - & - & - \\
\hline 21 & Eicosane & $38.2-47.3$ & - & - & - & - & - & - & - & - & - \\
\hline 22 & Heneicosane & $47.1-49.2$ & - & - & - & - & - & - & - & - & - \\
\hline & Total \%Normalized Areas & & 1.67 & 0.00 & 0.00 & 4.07 & 1.60 & 1.59 & 0.91 & 3.35 & 2.38 \\
\hline
\end{tabular}

Table A8. Hydrocarbon VOCs detected in RBDCOs.

\begin{tabular}{|c|c|c|c|c|c|c|c|c|}
\hline & Hydrocarbon & Retention Time & RBD CO-1 & RBD CO-2 & RBD CO-3 & RBD CO-4 & RBD CO-5 & RBD CO Old \\
\hline 1 & Butane + isomers & 4.2 & 0.05 & - & - & 0.13 & - & 2.94 \\
\hline 2 & Pentane + isomers & $4.6-6.1$ & 0.83 & 1.14 & 1.99 & 0.76 & 6.41 & - \\
\hline 3 & Hexane + isomers & $4.7-12.6$ & 1.12 & 9.49 & 16.43 & 13.23 & 3.28 & 3.17 \\
\hline 4 & Cyclopentane, methyl- & 5.3 & - & 0.22 & 0.72 & 0.23 & - & - \\
\hline 5 & Benzene + isomers & $5.7-47.2$ & 0.05 & - & - & - & - & 0.91 \\
\hline 6 & Heptane/heptene + isomers & $6.3-6.8$ & - & 0.24 & 0.04 & - & 0.69 & - \\
\hline 7 & Toluene & $9.11-9.3$ & 0.88 & 0.72 & 1.32 & 0.93 & 0.28 & 3.39 \\
\hline 8 & 1-Octene/octane + isomers & $10.7-21.6$ & - & - & 0.21 & - & 1.93 & - \\
\hline 9 & p-Xylene & $15.6-17.1$ & 0.40 & - & - & - & - & 1.05 \\
\hline 10 & Styrene & 16.9 & 0.91 & - & - & - & - & 0.10 \\
\hline 11 & Undecane + isomers & $21.7-23.8$ & 0.09 & - & - & - & 0.47 & 1.40 \\
\hline 12 & Nonane + isomers & $22.4-38.3$ & 0.34 & - & - & - & - & - \\
\hline 13 & 2-Octanol (Internal Standard) & 24.0 & 4.65 & 24.67 & 15.73 & 22.42 & 22.13 & 7.99 \\
\hline 14 & Decane + isomers & $25.1-37.5$ & 0.16 & - & - & - & - & - \\
\hline 15 & D-Limonene & 25.3 & 0.12 & - & - & - & 0.25 & 0.14 \\
\hline 16 & Dodecane + isomers & $27.0-35.5$ & 0.10 & - & - & - & - & - \\
\hline 17 & Naphthalene and derivatives & $33.4-53.6$ & 0.38 & - & - & - & - & - \\
\hline 18 & Dodecane & 34.4 & - & - & - & - & - & 0.56 \\
\hline 19 & Hexadecane & 34.6 & - & - & - & - & - & - \\
\hline 20 & Tetradecane + isomers & $36.5-43.6$ & 0.10 & - & - & - & - & 0.16 \\
\hline 21 & Eicosane & $38.2-47.3$ & 0.28 & - & - & - & - & - \\
\hline 22 & Heneicosane & $47.1-49.2$ & - & - & - & - & - & - \\
\hline & Total \%Normalized Areas & & 5.81 & 11.81 & 20.71 & 15.28 & 13.31 & 13.82 \\
\hline
\end{tabular}

\section{References}

1. Dayrit, F.M.; Dimzon, I.K.D.; Valde, M.F.; Santos, J.E.R.; Garrovillas, M.J.M.; Villarino, B.J. Quality characteristics of virgin coconut oil: Comparisons with refined coconut oil. Pure Appl. Chem. 2011, 83, 1789-1799, doi:10.1351/PAC-CON-11-04-01.

2. Saittagaroon, S.; Kawakishi, S.; Namiki, M. Aroma Constituents of Roasted Coconut. Agric. Biol. Chem. Tokyo 1984, 48, 23012307, doi:10.1080/00021369.1984.10866491. 
3. Dimzon, I.K.D.; Valde, M.F.; Santos, J.E.R.; Garrovillas, M.J.M.; Dejarme, H.M.; Remollo, J.M.W.; Dayrit, F.M. Physico-chemical and microbiological parameters in the deterioration of virgin coconut oil. Philipp. J. Sci. 2011, 140, 89-103.

4. Zhang, W.; Cao, X.; Liu, S.Q. Aroma modulation of vegetable oils-A review. Crit. Rev. Food Sci. 2020, 60, 1538-1551, doi:10.1080/10408398.2019.1579703.

5. Kellard, B.; Busfield, D.M.; Kinderlerer, J.L. Volatile off-flavour compounds in desiccated coconut. J. Sci. Food Agric. 1985, 36, 415-420, doi:10.1002/jsfa.2740360516.

6. Pai, J.S.; Lomanno, S.S.; Nawar, W.W. Effect of heat treatments on the volatile composition of coconut oil. J. Am. Oil Chem. Soc. 1979, 56, 494-497, doi:10.1007/BF02680186.

7. Santos, J.E.R.; Villarino, B.J.; Zosa, A.R.; Dayrit, F.M. Analysis of Volatile Organic Compounds in Virgin Coconut Oil and their Sensory Attibutes. Philipp. J. Sci. 2011, 140, 11.

8. Philippine National Standard: Virgin Coconut Oil (VCO); PNS/BAFPS 22:2007.ICS 67.200.10; Available online: http://spsissuances.da.gov.ph/index.php/da-philippine-national-standards/1087-pns-bafs-22-2007-vco-revised (accessed on 6 April 2021). 